\title{
Iatrogenesis and Medical Error: The Case for Medical Malpractice Litigation
}

by Barry R. Furrow, J.D.

D iscussions of medical malpractice seem to end up at either of two extremes: the trial lawyer's view that injured patients deserve compensation, with the treating physician the best source; and the doctor's view that such suits unfairly penalize judgmental errors while raising the costs of practicing medicine. The parties to this debate make different assumptions about the nature, purpose, and likely impact of malpractice suits; as a result, the issues are muddied rather than clarified. This article suggests that, viewed in light of recent studies of iatrogenic illness in hospital settings, malpractice litigation may help rather than hinder the quality of medical care delivered.

latrogenesis, defined as the undesirable side-effects of medical interventions, is not a new phenomenon. The major study undertaken by the Department of Health, Education and Welfare in 1973 noted that a substantial percentage of adverse medical outcomes occur as the result of treatment. ${ }^{1}$ Others have concluded that many surgical deaths are avoidable. ${ }^{2}$ Two recent studies have added fuel to the smoldering controversy over the nature and extent of such medical mishaps, drawing attention to a range of medical errors and raising again the question of the tort system's relationship with medical error. The two

Mr. Furrow is Visiting Professor of Law at the University of Michigan Law School in Ann Arbor, Michigan, and Professor of Law (on leave) at Washington College of Law, American University in Washington, D.C. Mr. Furrow is also a newly appointed Associate Editor of LAW. MFD. ICINE \& HEALTH CARE in charge of the column on Medical Malpractice. studies, in the NEW ENGLAND JOUR. NAL OF MEDICINE, focused upon surgical mishaps in one case ${ }^{3}$ and iatrogenic illness in a general medical service at a university hospital in the second. ${ }^{4}$

The first study, surveying avoidable adverse outcomes from colonic surgery, concluded that " $[t]$ he penalties for such misadventures turned out to be severe, with 10 times the mortality, seven times the average cost, and four times the length of hospitalization expected in average patients undergoing comparable but uncomplicated colonic surgical procedures." types of errors which occurred, 31 were "those of unnecessary, contraindicated, or technically defective surgical activity." Other sources of the medical "errors" were identified by the authors, admittedly in an impressionistic fashion, as misplaced optimism, a sense of unwarranted urgency, the urge for perfection, and the use of vogue therapies: all errors of commission. From a legal standpoint, according to the authors, "none appears to have involved negligence."7 The authors were concerned about their findings, and proposed that a legal safeguard was needed against malpractice suits for errors in judgment, i.e., "error simply related to flawed reasoning" as opposed to negli. gence. ${ }^{8}$ Malpractice suits only succeed, according to the authors, in driving into concealment the "forces that could help to reveal and control epidemiologic sources of error."9

The culprit of the study is made out to be the tort system, with fear of litigation blocking broader disclosure of hazards, better studies, and open discussion. The asserted link between medical error and malpractice is a curious one, following the authors' premises: (1) many severe iatrogenic events occur, (2) due primarily to physician judgmental error, (3) which errors could be minimized by better data collection and discussion, (4) except for the effect of malpractice litigation in stifling said reforms, even though (5) none of the examples which the authors cite involve negligence. It is as though a mandatory swipe at malpractice litigation is necessary to top off the study.

In light of recent studies of iatrogenic illness in the hospital setting, malpractice litigation may help rather than hinder the quality of medical care delivered.

The second study, of general medical services at a university hospital, monitored 815 patients during a fivemonth period in $1979 .{ }^{10}$ Of these, 290 (36 percent) had one or more iatrogenic illnesses, 76 (9 percent) had major complications, and of the 15 who died ( 2 percent of all patients and more than 5 percent of those with complications), iatrogenic illness was believed to be a contributing cause. The intervention categories were drugs, diagnostic and therapeutic procedures, and miscellaneous others. The authors' overall conclusion was that "the risk incurred during hospitalization is not trivial" and that "the risk of a serious problem may well have increased" in the last 20 years. "1 Causes mentioned included routine monitoring of a range of physiologic characteristics, often leading to earlier interventions than might have occurred in the past; use of a wide range 
of potent drugs; and therapeutic procedures in general. The authors made no judgment as to negligence and iatrogenesis. As in the first study, however, these authors issued a clarion call for better mechanisms "to assess the hazards of hospitalization in an ongoing manner," 12 for an intensified search for means to reduce the frequency and severity of iatrogenic events, and for a shared concern for deficiencies in medical review with in the hospital.

\section{Medical Error and Culpability}

The level of patient harm demonstrated by these recent studies raises the question of the interface of malpractice litigation with risk reduction, a relationship which the studies assumed was either detrimental or too insignificant to mention. However, a sophisticated view of tort litigation suggests that it may be a valuable ad. junct to other professional reforms and in fact can be a central force in promoting change. A brief summation of the kinds of medical error raised in these studies reveals suggestive connections between error and culpability.

Tort rules have traditionally attempted to render the plaintiff whole by forcing a defendant to pay compensation, with the justification that the defendant can fairly be taxed because of his "fault" in injuring the plaintiff. Two categories of "fault" are normally included within the category of malpractice: intentional harmful acts and negligent acts.

Willful harmful acts. Intentional torts include a knowing deviation, without good cause, from the professional or ethical norms of practice for the profession or from recognized procedures and techniques for treatment. The roots of the informed consent doctrine can be traced to the intentional tort of battery, for example, acknowledging the connection between a surgical "touching" and the knowing withholding of information from the patient. ${ }^{13}$ Also in this category are cases of excessive surgery, such as the infamous case of Dr. Nork, who performed countless surgical procedures which he knew to be unnecessary and which he also knew he was incompetent to perform. ${ }^{14}$

Negligent acts, as measured by professional standards. Negligence provides the usual basis for a malpractice action. It is defined as unskillful practice causing injury to the patient, as a result of a failure to exercise the "reasonable degree of skill, knowledge, and care" 15 appropriate under the circumstances. The reasons for a physi. cian's failure to follow an accepted standard can be many: inattentiveness on a particular occasion, even though he is a skillful, well-trained doctor; a systematic failure of training, in which a physician has not kept up with his field; or a personal inability of the physician to deal with this particular problem by, for example, operating outside his sphere of competence. Even though the particular physician

Discussions of professional regulation tend to downplay the role of malpractice litigation, portraying it as useful only for the sanction of gross violations of professional norms. In fact, such litigation should be viewed as a form of "microregulation" of undesirable practices.

has considered the consequences of treatment and has exercised his best judgment, his conduct is still measured by an external standard of the reasonable practitioner in his position.

The legal system has deemed it fair to hold a physician accountable for these two categories of medical errors in a malpractice suit. They imply that the physician has failed to conduct himself at that level of practice which his professional membership indicates he should have achieved, and which he presumably could have achieved, with diligence. In these two categories of error, the focus is upon the individual practitioner and his deviation, whethet intentional or negligent, from a norm. The types of error likely to be detected are those of the unethical or slipshod doctor, who is probably a cause of a small, although significant, percentage of harm. The types of medical errors revealed by the studies discussed above, however, tend to fall into neither of these categories, sug. gesting that there are at least two further categories of medical error, and their existence tests the limits of current malpractice doctrine.

Errors based upon professional shortcomings. Deficiencies within a medical specialty may cause iatrogenic harm. These may include problems of scientific ignorance, inadequate evaluation of diagnostic instruments and procedures before use, or failures to educate members. A medical specialty may be in its infancy, so that knowledge about etiologies of illness and techniques of treatment is incomplete. Those therapeutic techniques which are available may not yet have been sufficiently perfected to eliminate substantial risks of side effects. ${ }^{16}$

Although injury to a patient may be caused by the shortcomings of a particular therapist in a given case, it is not the individual's failure, but rather that of the profession as a whole which can fairly be said to have caused injury. We are therefore troubled, at least initially, by singling out the individual physician for liability. It is really a form of vicarious liability we are imposing, in which the profession is collectively at fault, but a particular therapist is being penalized for collective shortcomings. The causes cited by the studies suggest that errors in this category (e.g., vogue therapies, multiple drug administration) account for a significant percentage of the iatrogenic harms suffered. ${ }^{17}$

Errors related to work setting. The context of both studies, discussed above, the modern hospital, provides a fourth set of medical errors. While solo practice has long been the ideal in medical practice, physicians' need for a hospital connection has created the present form of practice, which is collegial, operating within hospitals and group practices. By 1975 , no physician would consider practicing without the resources that hospital affiliation brought, and one in four of the 330,000 active physicians practiced full-time in a hospital. ${ }^{18}$ In that same year, over 18 percent of all active physicians practiced in groups of three or more. ${ }^{19}$ Almost 80 percent of the incidents that lead to malpractice claims occur in hospitals, reflecting the primacy of the hospital as the locus of most medical practice. ${ }^{20}$ The work setring of the hospital provides a context in which "persistent and powerful demands cause the individual to 
behave in a certain way regardless of his personal qualities." 21 These de. mands can lead to peer pressure against questioning a colleague's judgment or informing on his errors. Alternatively, the incentive structure can be changed in directions which tend to uncover errors. ${ }^{22}$

Discussions of professional regula. tion tend to downplay the role of malpractice litigation, portraying it as useful only for the sanction of gross violations of professional norms. In fact, such litigation should be viewed as a form of "microregulation" of undesirable practices. The legal system essentially acts as a form of control over activities that cause injuries. It holds those involved in an activity accountable for staying informed about progress in a field, and judges the standards by which the activity is performed. In malpractice cases, the customary practice of the profession generally determines the standard of care against which an individual's behavior will be judged. The medical profession has the privilege of setting its own standard of conduct, by merely adopting and acknowledging its own treatment practices. ${ }^{23}$

The justification for this has been courts' perceived lack of expertise in judging another profession, and their fear of imposing liability based upon an uninformed judgment. Where the customary practice of the profession has been inadequate, dangerous, or out-of-date, the plaintiff has lacked a doctrinal basis for attacking the standard itself. On rare occasions, courts have recognized that a customary medical practice may be negligent. Thus, in Helling v. Carey, ${ }^{24}$ the Washington Supreme Court held that the defendant ophthalmologists were negligent as a matter of law in failing to administer a simple glaucoma test, despite uncontradicted expert testimony that it was universal practice not to so test patients under the age of 40 .

Helling, and a minority of other cases, ${ }^{25}$ have involved a therapy or diagnostic procedure which was readily understandable by lay persons. This has allowed the trier of fact to weigh - without expert testimony the relative risk of injury caused by the procedure and by its omission. These cases have not been followed by most jurisdictions, since courts are normally reluctant to set their own standards of care in place of those established by the profession, especially in complex cases. However, courts should be more willing to take a hard look at the customary practice where a plaintiff can produce some evidence that the practice is out-of-date or ineffective and thereby dangerous.

Cases falling into the latter two categories of medical errors have been more troublesome to courts attempting to make tort law responsive to changes in medical practice. Judicial expansion of malpractice liability, making physicians accountable for a range of medical errors, has run counter to legislative reforms in the malpractice area. Over the past decade, state legislatures responding to the "malpractice crisis" have abrogated or restricted the operation of legal doctrines from res ipsa loquitur to informed consent. ${ }^{26}$ But judicial recognition of the centrality of the hospital setting has marked several recent landmark cases. Thus, hospitals have been subjected to an expansion of the respondeat superior doctrine and held responsible for the alleged negligence of physicians practicing within them, even when the physicians were independent contractors. ${ }^{27}$ An alternative theory of "corporate negligence" has been based on the premise that a hospital owes its patients a duty to exercise ordinary care in supervising its staff. 28

A movement toward strict liability for hospital services, analogous to that which exists for some products, may also be developing. Some hospitals have been held liable for harm caused by medical instruments used in treating patients. ${ }^{29}$ Courts have usually distinguished the rendition of professional services from the sale of goods. ${ }^{30}$ In recent cases, however, courts have begun to examine the basis for strict liability in the medical context. In Hoven v. Kelble, ${ }^{31}$ the Supreme Court of Wisconsin, while rejecting strict liability for medical services, noted the similarity between consumers purchasing products and consumers seeking medical care:

The typical purchaser of medical services cannot evaluate the quality of care offered because medical services are complex and infrequently bought. The medical care market gives the purchaser little assistance in enabling the purchaser to evaluate what he or she is buying. It is generally the physician - not the patient - who determines the kind of services to be rendered and how often .... The physician is in a better position than the patient to determine and improve the quality of the services, and the patient's reliance on the doctor's skill, care and reputatiōn is perhaps greater than the reliance of the consumer of goods. ${ }^{32}$

In Johnson v. Sears, Roebuck \& Company, ${ }^{33}$ a federal district court held strict liability to be a permissible theory of recovery for defects in mechanical and administrative services in hospitals. This court assumed, without deciding, that strict liability would "not apply to professional medical services by doctors." 34 But it reasoned that such an exemption should

There is a trend toward linking tort liability with the predictability of harmful results and the ability to discover and prevent them. Expanded liability provides a substantial incentive to providers to improve risk management programs or to face the bad publicity and increased insurance premiums which litigation brings.

not apply to "those services which hospitals perform for both doctors and patients," because of the "public interest" in having these services "performed properly." 35

The Illinois Supreme Court has held that a hospital may be found strictly liable for the quality of blood which it provides for transfusion. ${ }^{36}$ Similarly, a Florida appellate court held that a supplier of blood for trans. fusion could be held liable for resulting harm unless it could be factually determined that impurities in the blood could not be detected or prevented. ${ }^{37}$

These cases represent a trend toward linking tort liability with the 
predictability of harmful results and the ability to discover and prevent them. Courts are coming to recognize that hospitals are in the best position to monitor iatrogenic effects traceable to their own services, and that expanded liability provides a substantial incentive to providers to improve risk management programs or to face the bad publicity and increased insurance premiums which litigation brings. Expanded liability may therefore create a generalized pressure to alter the work setting in favor of better recordkeeping, more frequent conferences on adverse outcomes, more consultations, and evaluation of procedures not only for cost, but also for iatrogenic impact.

Other malpractice law developments may also result in alteration of professional attitudes and practices. The doctrine of informed consent, while still bitterly resisted by parts of the medical profession, ${ }^{\mathbf{3 8}}$ has had some impact on medical disclosure practices, resulting in more clearly articulated disclosures by physicians of hazards and alternatives. ${ }^{39}$ Legal rules, if they are seen as technical and therefore only mechanically applied, are of little use, but when the values inherent in such doctrines as informed consent become internalized, there will be more changes and further reforms.

\section{Medical Errors and Predictability}

The tort law concept of foreseeability of harm provides the core justification for a concept of medical culpability which can encompass all four categories of medical errors discussed above. Foreseeability involves a prediction, at a time prior to the occurrence of an injury, of the type of injury that might result from a treatment error, of its severity, and of the probability that such an injury will occur. 40 The use of "foreseeability of harm" as the dominant test of a duty to prevent injury requires the actor either to take precautions or to face liability, where harm is likely to occur and the victim has neither consented to nor can avoid the harm.

The focus of predictability of risk moves us from the individual within a professional group to the capabilities of the group itself, or to the institutional setting, the hospital. Culpability is linked to predictability and to the ability of the profession to alter the level of risk, which it is able to predict. $^{41}$

In each case, the test for foreseeability will be derived from the increased predictive powers of modern medicine, through its new technologies and the use of statistics. As institutions come to know more precisely the extent of the risks associated with their activities, the ascription of responsibility and culpability becomes possible and fair. ${ }^{42}$ Even if a medical provider cannot predict the whole range of risks associated with his services, he is in a better position, compared to the patient, to detect and correct as many as possible. It is a question of the relative advantage of the parties. Judicial expansion of liability, whether through the application of the doctrine of strict liability, res ipsa loquitur, or informed consent, assumes that the physician controls his own acts. It further assumes that the physician has some power to diminish the risk to parients, either by his own initiative or by aggregating resources with other members of the profession.

Tort law, crude and arbitrary as it may seem to some, has a role to play in exposing medical errors. The malpractice suit can signal the need for change in the habits of the individual practitioner or in the institutional practices of the hospital. It may help to expose the ethical renegades, the Dr. Norks; it may provide direct deterrent effects, through dollar judgments and the psychic costs of involvement in litigation. ${ }^{43}$ More importantly, litigation may articulate new duties, validating existing norms or promoting the centrality of new ones. It may articulate new concepts of responsibility and require the medical specialities to re-examine their diagnostic procedures and treatment modalities. It may, by expanding the liability of institutions which increasingly dominate health care delivery, alter the work setting. Litigation has the advantage of not requiring a new piece of legislation or new administrative machinery to put its reforms into operation. It can be triggered by a single plaintiff, and once its intervention is sought, a court must act on the case before it.

The recent studies of iatrogenesis suggest that the problem is real and substantial, but that the medical profession still seeks to avoid linking culpability with medical error. Nor is it uncommon to blame the legal system for medicine's own tardiness in implementing effective monitoring of iatrogenic harms. Malpractice suits may be the best source of regulation currently available for iatrogenic outcomes in the health care system. Proposals to reform the medical malpractice system will be inadequate if they ignore this primary need to deter bad medical practices. ${ }^{44}$

The medical establishment needs to be made more aware of the risks it creates. Accordingly, future reforms must note the real problems of medical ertor and the incentives for correction provided by malpractice litigation. Any "no fault" system or national health insurance plan, if it seeks to reduce medical malpractice and ensuing litigation, must also provide an alternative means of detering iatrogenic outcomes.

\section{References}

1. Pocincki, L.S., Dogger, S.J., Schwartz, B.P. The Incidence of latrogenic Injuries, in DE. PARTMENT OF HEALTH EDUCATION AND WEL.

FARE, APPENDIX: REPORT OFTHE SECRETARY'S COMMISSION ON MEdICAL MaLPRACTICE (DHEW Pub. No. (OS) 73-89, U.S. Gov't Printing Office, Washingron, D.C.) at 50, 51 . 2. A study, jointly sponsored by the American College of Surgeons and the American Surgical Association. concluded that 796 of the

1696 deaths or complications arising out of

1,493 surgical operations examined were avoid. able. C. Child, The CRITiCal Incident Study of SURGical. Deaths and Complications 1973.1975 (1975), discussed in Study on Qualizy of Surgery Is Unveiled, MEDICAL WORLD NEWS, pp. 24-25 (January 26, 1976); see also Brody, )., Incompetent Surgery ls Found Not lsolated. NEW YORK TIMES, January 27, 1976, at I, col. 6. A study of the death rare in Los Angeles County during a doctors' work slowdown confirmed a drop in the death rate, linked to the sharply reduced amount of elective surgery performed during the slowdown. See Death Rate in L.A. Fell in Slowdown by Doctors, WASHINGTON POST, October 20, 1978 at A6, col.5.

3. Couch, N.P., et al. The High Cost of Low-Frequency Events, NEW ENGLAND JOURNAL OF MEDICINE 304(11):634-37 (March 12. 1981)

4. Steel, K., et al, latrogenic Illness on a

General Medical Service at a University Hospital.

NEW ENGLAND JOURNAL OF MEDICINE 304 (11):

638.42 (March 12, 1981).

5. Couch, et al, supra note 3 , at 634

6. Id. at 635 .

7. Id. at 637 .

8. Id

9. Id

Continued on page 41 


\section{b) Staff Privileges}

Behrsin AJ, Housestaff Stipends and the "Fellowship" Exclusion Under Section 117 of The Internal Reverue Code, JOURNAL OF COLleGE AND UNIVERSITY LAW 8(1): 131 (1981-82).

Feliu AG, Discharge of Professional Employees: Protecting Against Dismissal for Acts Within a Professional Code of Ethics, Columbia Human Rights Law REVIEW 11(2): $149-88$ (Fall-Winter 1979-80).

Exclusive Contracts and Hospital-Based Physicians, TeXas Medicine 77(7): 68-71 (July 1981) [9-175].

Medical Housestaff: Scholars or Working Stiffs? Pacific LaW Journal 12(4): $1127-46$ (July 1981).

\section{c) Withbolding Treatment}

Cushing M, Treatment Beyond Death? AmERICAN JOURnal of NuRSING 81(8): 1527-28 (August 1981) [9-743].

Thrasher JE, McNicholas A], NoCode Orders, Journal of THE FLORIDA Medical Association 68(7): 487-88 (July 1981) [9.775].

\section{Human Experimentation}

Ackerman TF, Moral Duties of Investigators toward Sick Children, IRB 3(6): 1-5 (June/July 1981) [9-724].

Cohen JM, The Benefits of Professional Staff for IRBs, IRB 3(6): 8.9 (June/July 1981) $[9-726]$.
Holder AR, Case Study: Can Amniocentesis Be Performed Solely for Research? IRB 3(6): 6-7 (June/July 1981) [9-725].

Levine RJ, Commentary: A Primaty Reviewer System, IRB 3(6): 9-10 (June/July 1981) [9.727].

Petricciani ], Comparison of Regulations for IRBs and Informed Consent Published by FDA on January 27, 1981 and by HHS on January 26, 1981 (unpublished manuscript) $21 \mathrm{pp}$. [9-762].

Two Views of the New Research Regulations: Veatch RM, Protecting Human Subjects: The Federal Government Steps Back; Wigodsky HS, New Regulations, New Responsibilities for Institutions, Hastings Center Report 11(3): $9-14$ (June 1981) [9-184].

\section{Medical Malpractice References Continued from page 7}

10. Steel, et al., supra note 4 , at 638 .

11. Id. at 641

12. Id.

13. See genetally ]. KING. THE LAW OF MEDI CAL MALPRACTICE IN A NuTTSHELl (West Publishing Co., St. Paul) (1977) at 136.

14. Gonzales v. Nork, No. 228566 (Calif.

Super. Ct., Sacramento County, November 19. 1973), for excerpts, see S. LAW, S. POLAN, PAIN AND PROFIT: THE POLITICS OF MALPRACTICE (Harper \& Row, New York) (1978) at 215.45.

15. Bardessono v. Michels, 478 P. $2 \mathrm{~d} 480,484$ (Cal. 1970).

16. See Gotovitz, S., Macintyre, A., Toward a Theory of Medical Fallibility, HASTINGS CENTER REPORT 5(6): 13 (December 1975).

17. Couch, et al., supra note 3, at 636; Steel, et al., supra note 4 , at 639.

18. S.]. RESIER, MEDICINE AND THE REIGN OF TeChNOLOGY (Cambridge University Press,

New York) (1981) at 156

19. Id. at 157

20. J. Gunther, The Malpractitioners (Anchor Press/Doubleday, New York) (1978) at 7 , citing results of a study conducted by the Insurance Services Office

21. E. Freidson, Profession of Medicine: A STUDY OF THE SOCIOLOGY OF APPLIED KNOWLEDGE (Harper \& Row, New York) (1970) at 94 .

22. See Havighurst, C.C., Tancredi, L.R., Medical Aduersity Insurance: A No-Fault Approach to Medical Malpractice and Quality Assur ance, INSURANCE LAW JOURNAL 612:69-100 (February 1974), for a discussion of an attempt to couple fnancial incentives through insurance with risk disclosure. See genetally INSTITUTE OF Medicine. National ACADEMY OF SCIENCES. BEYOND MALPRACTICE: COMPENSATION FOR MEDICAL INJURIES (1978).

23. W. PROSSER. HANDBOOK OF THE LAW OF TORTS, 4th ed. (West Publishing Co., St. Paul) (1971) $\$ 30$.
24. Helling v. Carey, 519 P.2d 981 (Wash. 1974)

25. See, e.g., Lundahl v. Rockford Mem. Hosp. Ass'n, 235 N.E.2d 671, 674 (Ill. App. 1968) ("what is usual or customary procedure might itself be negligence").

26. See generally Law, Polan, supra note 14 at 97.119 .

27. Beeck v. Thesson General Hosp. 500 P.2d 1153 (Ariz. App. 1972).

28. Darling v. Charleston Community Mem.

Hosp. 2Il N.E.2d 253 (Ill. 1965), cert. denied, 383 U.S. $946(1966)$

29. See 54 ALR 3d 258 for a list of cases.

30. See B. Furrow Malpractice IN

PSYCHOTHERAPY (1980) at 82.

31. Hoven $v$ Kelble, 256 N.W.2d 379 (Wisc. 1977).

32. Id. at 391 (footnote omitted).

33. Johnson v. Sears, Roebuck \& Co., 355 F.

Supp. 1065 (E.D. Wisc. 1973).

34. Id. at 1066

35. Id. at 1067

36. Cunningham v. MacNeal Mem. Hosp., 266 N.E.2d 897 (III. 1970)

37. Russell v. Community Blood Bank, 185 So.2d 749 (Fla. App. 1966).

38. See, e.g., Grudner. On the Readability of Surgical Consenc Forms, NEW ENGLAND JOUR. NAL OF MEDICINE 302(16): 900-02 (April 1980)

39. Doctrinal changes in tort law have al. tered the physician-patient relationship in the direction of fuller disclosure. See Novack, Changes in Physicians' Attitudes toward Telling the Cancer Patient, JOURNAL OF THE AMERICAN Medical association 241(9):897,898 (March 1979), noting that in 1961,12 percent of surveyed physicians generally told a patient about cancer diagnosis; by 1977,98 percent re. ported a general policy of telling the patient. Whether the patients understand the information is another question. See Cassileth, B.R., et al, Informed Consent - Why Are its Goals Imperfectly Realized? NEW ENGLAND JOURNAL OF MED ICINE 302(16):896 (1980). But see Annas, G.J. Editorial: The Goals of Informed Consent MEDICOLEGAL NEWS 8(3): 13 (June 1980)

40. See Judge Learned Hand's famous statement of the negligence calculus in United States v. Carroll Towing Co., 159 F.2d 169 (2nd. Cir. 1947). "[T]here can be no. . general rule, when we consider the grounds for liability... The . . . duty . . . to provide against resulting injuries is a function of three variables: (1) The probability [of harm]; (2) the gravity of the resulting injury . . ; (3) the burden of adequate precautions. Possibly it serves to bring this nocion into relief to state it in algebraic terms; if the probability be called $P_{i}$ the injury, $L_{i}$ and the burden, B; liability depends on whether $B$ is less than $L$ multiplied by $P$ : i.e., whether B<PL." (at 173).

41. See O'Connell. J., Expanding No-Fault Beyond Auto Insurance: Some Proposals, VIRGINIA LAW REVIEW 59(5):749-829 (May 1973) at 790-94, for an analysis of the connec tion between culpability and predictability of risk.

42. Twiss, The Problem of Moral Responsitility in Medicine, JOURNAL OF MEDICINE AND PHILOSOPHY 2:330, 365 (1977); Baram. Technology Assessment and Social Control, SCIENCE 180:465 (May 1973).

43. Schwartz, Komesar, Doctors, Damages and Deterrance: An Economic View of Medical Malpractice, NEW ENGLAND JOURNAL OF MED! CINE 298(22):1282 (1978). See generally $G$. Calabresi, The Costs of Accidents: A LEGAL AND ECONOMIC ANALYSIS (Yale Universiry Press, New Haven) (1970).

44. See Havighurst, C.C., Medical Adversizy Insurance: Has Its Time Come? DUKE LAW JOUR NAL 1975(6):1233-80 (January 1975). 